\title{
Oncolytic virus therapy for cancer
}

This article was published in the following Dove Press journal:

Oncolytic Virotherapy

23 September 2013

Number of times this article has been viewed

Joe Goldufsky'
Shanthi Sivendran
Sara Harcharik
Michael Pan ${ }^{4}$
Sebastian Bernardo
Richard H Stern
Philip Friedlander
Carl E Ruby',2
Yvonne Saenger
Howard L Kaufman ${ }^{4,2}$
Departments of 'Immunology \&
Microbiology and ${ }^{2}$ Surgery, Rush
University Medical Center, Chicago IL,
USA ${ }^{3}$ Hematology/Oncology Medical
Specialists, Lancaster General Health,
Lancaster, PA, USA, and Departments
of ${ }^{4}$ Medical Oncology and ${ }^{5}$ Radiology,
Tisch Cancer Institute, The Mount
Sinai School of Medicine, New York,
NY, USA

Correspondence: Howard L Kaufman Rush University Medical Center, 1725 W Harrison Street, Room 845,

Chicago, IL 606I2, USA

$\mathrm{Tel}+$ I 3129420600

Fax + I 312942060 I

Email howard_kaufman@rush.edu

\begin{abstract}
The use of oncolytic viruses to treat cancer is based on the selection of tropic tumor viruses or the generation of replication selective vectors that can either directly kill infected tumor cells or increase their susceptibility to cell death and apoptosis through additional exposure to radiation or chemotherapy. In addition, viral vectors can be modified to promote more potent tumor cell death, improve the toxicity profile, and/or generate host antitumor immunity. A variety of viruses have been developed as oncolytic therapeutics, including adenovirus, vaccinia virus, herpesvirus, coxsackie A virus, Newcastle disease virus, and reovirus. The clinical development of oncolytic viral therapy has accelerated in the last few years, with several vectors entering clinical trials for a variety of cancers. In this review, current strategies to optimize the therapeutic effectiveness and safety of the major oncolytic viruses are discussed, and a summary of current clinical trials is provided. Further investigation is needed to characterize better the clinical impact of oncolytic viruses, but there are increasing data demonstrating the potential promise of this approach for the treatment of human and animal cancers.
\end{abstract}

Keywords: cancer, gene therapy, oncolytic therapy, virus, treatment

\section{Introduction}

Viruses provide a unique platform for the treatment of cancer. Viral infection has intrinsic cytopathic effects, inducing cell death and mediating cellular dysfunction. In addition, the viral genome can easily accommodate modifications that increase viral tropism to neoplastic cells, enhance selective viral replication and lytic capacity, alter viral pathogenicity, and induce host antitumor immunity. These features are the foundation for the use of viruses in cancer therapeutics. The ability to generate virions rapidly and genetically engineer additional genes that promote antitumor immunity, increase tumor cell susceptibility to ionizing radiation or cytotoxic chemotherapy, and increase patient safety, are all major advantages of oncolytic viruses.

Within the past decade, the feasibility of oncolytic viruses has been nicely demonstrated in numerous preclinical tumor models, with clinical evidence of their therapeutic effectiveness in early-phase and late-phase clinical trials. By taking these modified oncolytic viruses from bench to bedside and back again, the field has seen rapid advancements in the treatment of numerous solid and hematological cancers. Currently in the United States, several oncolytic platforms are undergoing Phase III clinical trials, including but not limited to, granulocyte-macrophage colony-stimulating factor (GM-CSF)-expressing herpes simplex virus type 1, vaccinia, and reovirus. Furthermore, a modified adenovirus, H101 (Sunway, Shanghai, People's Republic of China), was approved in the People's Republic of China after a Phase III trial showed 
that patients with advanced head and neck squamous cell carcinoma treated with H101 and chemotherapy demonstrated a $79 \%$ objective response rate compared with a $40 \%$ response rate with chemotherapy alone. ${ }^{1}$ However, this trial did not report overall survival. While the feasibility of oncolytic viruses has been demonstrated in numerous preclinical tumor models, clinical evidence of therapeutic effectiveness has been largely confined to several small early-phase clinical trials. Despite these encouraging developments, there are several challenges to the use of viral vectors in cancer patients, including innate host antiviral immune responses, pathogenicity of some viral vectors, and incomplete targeting to all sites of established tumors.

Recent advances in viral genome sequencing and elucidation of viral protein function, combined with a better understanding of tumor genetics and tumor immunology, have renewed enthusiasm for oncolytic virus therapy. Elements of tumor tropism determinants have been better characterized, resulting in improved tumor targeting and increased lytic properties to produce oncolytic vectors with tumor-specific virulence. The ability to delete pathogenic viral genes has added an element of increased safety for the clinical development of oncolytic viral therapy in the clinic. Furthermore, progress in understanding the genetic basis of individual tumor cells and new insights into the interaction between tumor cells and the host immune system have aided in designing optimal clinical trials and new therapeutic strategies. This review describes both the advantages and disadvantages of some of the more commonly utilized viral vectors (Table 1) and the preclinical strategies being used to improve their therapeutic potential. In addition, this review highlights some of the important clinical trials (Table 2), and briefly discusses some of the future directions for this emerging area of oncolytic virus therapy.

\section{Oncolytic adenovirus}

\section{Basic virology}

The adenovirus is a nonenveloped, linear, double-stranded DNA virus with a genome size of approximately $30-38 \mathrm{~kb}$. These viruses consist of 60-90 nm nonenveloped particles with icosahedral symmetry. The virus was initially isolated from adenoid cell cultures in the 1950s, and was thus named "adenovirus". Adenoviruses are composed of 52 distinct serotypes, which can be categorized into five subgroups (A to F) based on their ability to agglutinate red blood cells and their oncogenic potential in rodents. Viruses in subgroup A are characterized by induction of tumors with a short latency, whereas viruses in subgroup B are only weakly oncogenic.
Adenoviruses in subgroup $\mathrm{C}$, including the well defined adenovirus- 2 and adenovirus-5, and subgroups D, E, and F, are nononcogenic. Human adenoviruses can transform rodent cells, but are not oncogenic in human cells. Viral particles enter cells slowly through a two-stage mechanism that involves interaction of a capsid fiber protein with a variety of cell surface receptors, including major histocompatibility complex class I molecules and the coxsackie virus and adenovirus receptors (CAR). Internalization is mediated by cellular integrins through a receptor-mediated endocytic process that releases viral particles into the cytoplasm. The virus then sequentially uncoats, releasing a spherical particle that enters the nucleus as a viral DNA-histone complex. Viral replication occurs in the nucleus of infected cells in an early and late phase. Viral DNA replication is regulated by virus-encoded transacting regulatory elements. The immediate early phase is characterized by transcription of the $E 1 A$ gene that is required for transcriptional activation of early genes. The early genes include E1B, E2A, E2B, E3, E4, and several other virion proteins. The E1B and E1A proteins cooperate to transform cells by forming a complex with the retinoblastoma gene product, $\mathrm{pRb}$ and $\mathrm{p} 53$, respectively. E3 protein products include several proteins that modulate apoptotic processes in effector $\mathrm{T}$ cells and help the virus escape immune-mediated clearance. The late genes largely encode additional virion proteins.

The virus is ubiquitous in human and animal populations and is endemic throughout the year. Adenovirus transmission occurs through the fecal-oral and aerosol routes, and can also be transmitted through direct contact with blood or inoculation to the conjunctiva. Human infection generally involves the respiratory system, gastrointestinal tract, and the eye. Typical adenovirus infections are asymptomatic in immunocompetent adults, with most individuals demonstrating antiviral immunity with detectable antiadenoviral antibody titers by the age of 15 years. The virus may cause limited respiratory, gastrointestinal, or ocular illnesses in newborns and immune-suppressed patients. Adenoviruses can infect a variety of cell types, and it is possible to delete genes involved with replication and insert genes encoding metabolic, enzymatic, or immune-modulating genes for gene therapy purposes. The ease of genetic manipulation has made the adenovirus popular for therapeutic development, but strong and often pre-existing adenovirus immunity limits the effectiveness of these vectors.

\section{Preclinical optimization}

Replicating adenoviruses have so far demonstrated limited efficacy as single therapeutic agents in the clinical setting. ${ }^{2}$ 


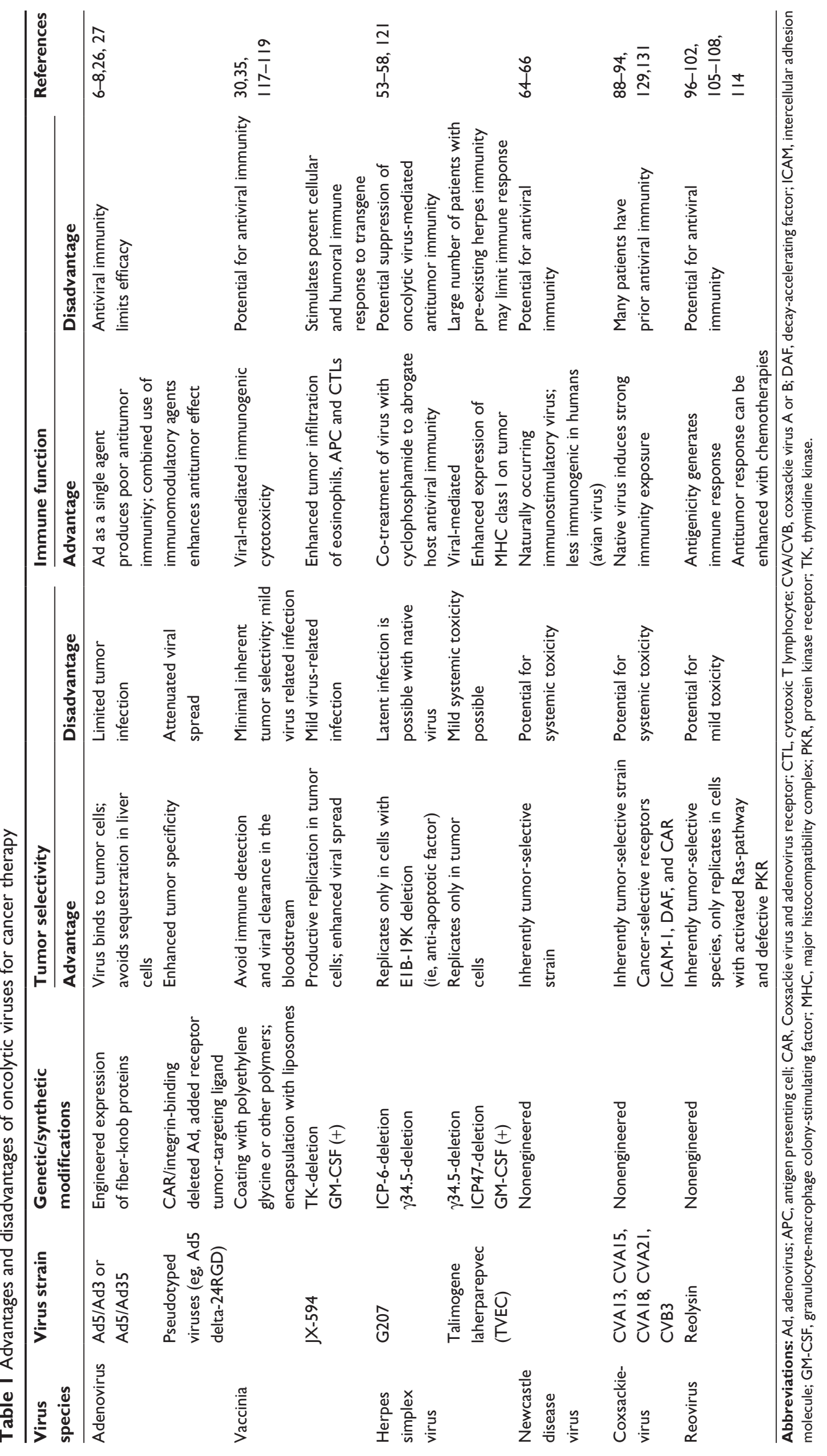




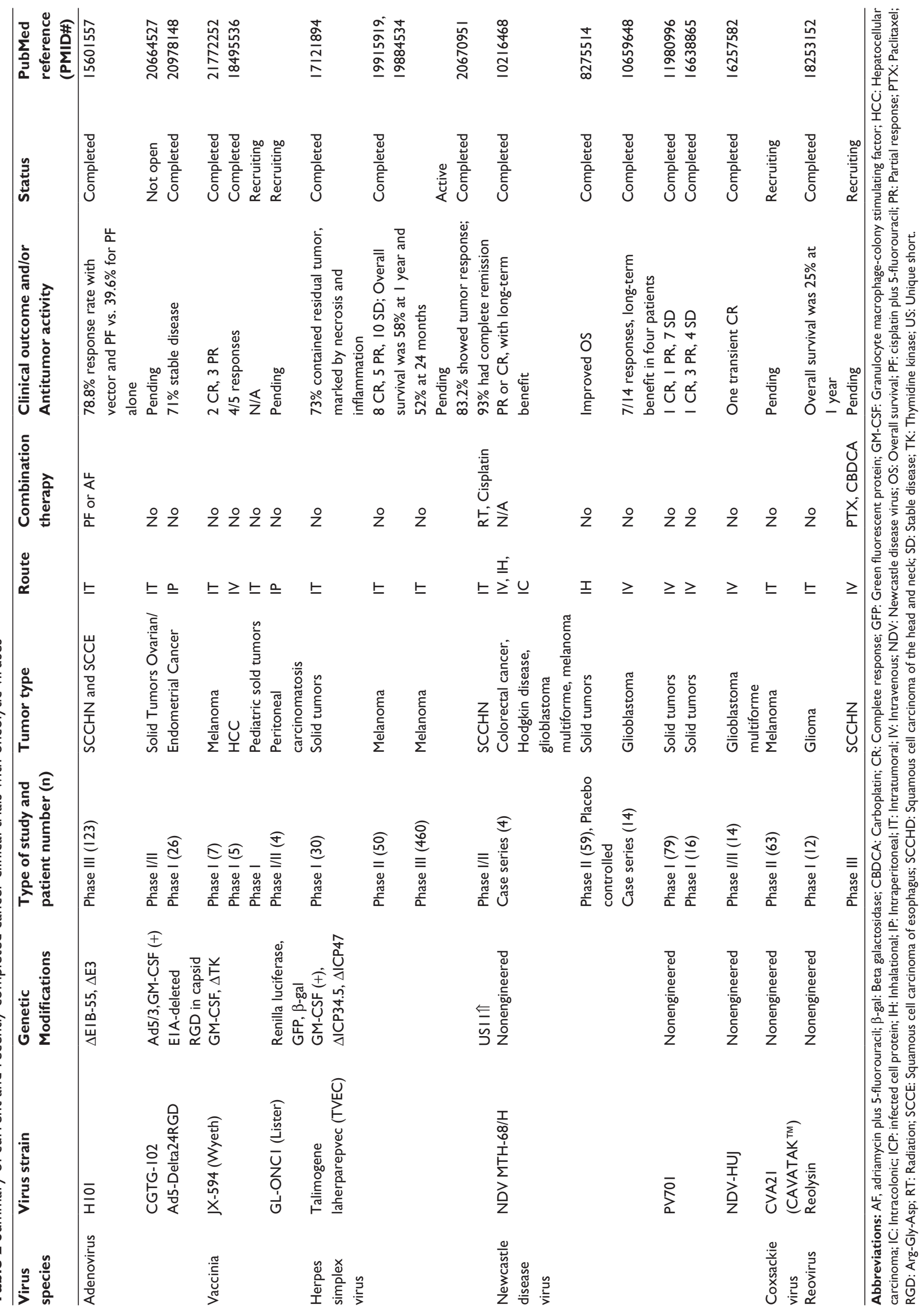


In the 1950s, early clinical trials investigating the therapeutic potential of nonengineered oncolytic adenoviruses were carried out in patients with cervical cancer. ${ }^{3}$ Of the various adenovirus particles administered, only live viable virus showed tumor necrosis, while tissue culture fluid or heatinactivated virus had no effect. In addition, early studies evaluated various routes of virus delivery (ie, intratumoral injection, arterial infusion into the tumor, a combination of the two, or intravenous injection), and no significant toxicities were reported with the different routes. In these early trials, only limited clinical responses were observed, and all patients eventually succumbed to their cancer. ${ }^{3}$ Recent progress in the genetic manipulation of adenoviruses and combination studies with other therapeutic modalities has started to show more promising results.

One reason for the lack of efficient therapeutic response associated with early conditionally replicative adenoviruses can be the absence of the primary adenovirus receptor (CAR) on some cancer cells, as has been reported in gastrointestinal, pancreatic, ovarian, and hormone-refractory prostate cancers. The use of adenoviruses have also been associated with less potent antitumor immunity, which may be based, in part, on the high frequency of pre-existing antiadenoviral antibody responses in humans. Specific strategies to enhance CAR-independent transduction of conditionally replicative adenovirus-refractory cancer cell types and improve tumorspecific immunity have utilized modifications to the viral coat to induce better cancer selectivity and provide proinflammatory signals. Among the factors used are viral fiber modifications, switching serotypes, constructing mosaic vectors, and bridging molecule-based targeting. Adenovirus-35 is a strain that utilizes CD46, rather than CAR, as the primary receptor for initial adsorption and entry. ${ }^{4,5}$ The tumor tropism of adenovirus- 35 has been used to construct a more selective vector for viral delivery. Another strategy that has been evaluated in preclinical models is modification of various capsule regions, typically in the "knob" domain, which augments the affinity and oncolytic effects of the virus in CAR-negative cancer cell lines. For example, an effective fiber modification incorporated a partial peptide sequence of fibronectin containing an argine-glycine-aspartate-4C (RGD-4C) motif into the H1 loop of the fiber-knob region and was found to enhance the oncolytic effects in CAR-negative pancreatic cancer and other gastrointestinal tumor cell lines. ${ }^{6-8}$

Investigators have also combined new adenoviruses and capsule modifications to generate mosaic vectors that employ multiple binding motifs from different parental viruses, and these vectors may also incorporate additional targeting peptides. These pseudotyped or genetically modified adenoviruses take advantage of a wider host cell range with higher transduction efficiency compared with vectors that target a single receptor. This enhanced infection of mosaic conditionally replicative adenoviruses has resulted in augmented oncolytic effects. ${ }^{9}$ Another approach for enhancing adenovirus targeting is the use of high affinity antibodies to target specific receptors on the tumor cell surface. A novel strategy utilized an antibody fusion construct in which one antibody targeted an adenovirus capsid protein and the other targeted the folate receptor, a ligand overexpressed on the surface of ovarian, lung, breast, and brain tumor cells. ${ }^{10}$ This vector demonstrated enhanced selectivity and stronger adenovirus affinity for the targeted cell. ${ }^{10-12} \mathrm{~A}$ drawback to this method is the loss of antibody fusion on viral progeny, limiting the ability to amplify targeting throughout the tumor microenvironment. ${ }^{10,13}$

Further regulation of adenovirus target cell specificity can be accomplished by introducing mutations in essential viral replication genes that restrict replication in normal cells but allow replication in cancer cells. For example, the ONYX015 adenovirus contains a deletion of the E1B transforming region, which sequesters its replication to cancer cells that are deficient in normal $\mathrm{p} 53$ function. ${ }^{14-16}$ Tumor specificity is further reinforced in ONYX-015 with its late viral RNA export, which restricts viral replication to tumor cells with aberrant cellular antiviral defenses. ${ }^{17}$ Another adenovirus adaptation for cancer-specific targeting involves use of a selective promoter-based conditionally replicative adenovirus, in which a tumor-specific promoter controls expression of the viral genes necessary for replication. As a result, the virus can replicate only in cells where the controlling promoter is active. For example, CN706 possesses a prostate-specific antigen promoter-driven E1 expression cassette, which limits replication of conditionally replicative adenovirus to prostate cancer cells in an androgen-dependent manner. ${ }^{18}$

An important goal in adenovirus gene therapy for cancer is amplification of the viral infection to nearby uninfected cells, in some cases through direct infection by progeny virions and in other cases through a bystander effect. ${ }^{19,20}$ Intrinsic barriers within the tumor microenvironment, such as dense intratumoral connective tissue and induction of antiviral immunity, can impair these processes. Alteration of the microenvironment by administering exogenous enzymes directly to the tumor or by equipping viruses to encode recombinant enzymes can facilitate viral spread. For example, delivery of a hyaluronidase-expressing oncolytic adenovirus showed improved dissemination and therapeutic 
activity in a human melanoma xenograft model by enzymatically targeting hyaluronan, a sulfated glycosaminoglycan component of the tumor extracellular matrix. ${ }^{21}$ Another approach that has been used to enhance viral potency has been to arm a conditionally replicative adenovirus with transgenes that promote antitumor activity through other mechanisms, including use of antiangiogenesis and immunostimulatory genes. ${ }^{22-25}$ Evasion of the immune system has been accomplished by the use of chemical polymers or polyethylene glycol to coat conditionally replicative adenoviruses, which in turn increased local virus delivery to tumor sites. ${ }^{26,27}$ While these approaches have demonstrated therapeutic activity in murine models, only a few have entered clinical trials, and these will be described later.

\section{Oncolytic vaccinia virus Basic virology}

Vaccinia virus is a member of the poxvirus family and exists as an enveloped viral particle that contains a linear doublestranded DNA genome. The poxviruses are among the largest mammalian viruses, and the genome consists of a nearly $200 \mathrm{~kb}$ genome. The vaccinia genome is regulated by a series of early, early/late, and late viral promoters that control initial uncoating, DNA replication, and reassembly of immature virion particles. In contrast with adenovirus, the entire life cycle of vaccinia replication occurs in the cytoplasm, and this abrogates concern about insertional mutagenesis when infecting cells with vaccinia. Viral replication is generally rapid, with cell lysis typically complete within 7 hours of infection. Vaccinia also encodes proteins that halt cellular transcription and translation, as well as proteins that interfere with interferon-gamma to help the virus evade immune detection. Vaccinia virus naturally displays tropism towards a wide range of mammalian and nonmammalian cell types, making it an attractive vector for experimental use. Vaccinia virus is considered a minor human pathogen and has been associated with severe skin reactions in patients with eczema and can cause systemic illness in immunocompromised individuals. The virus induces a potent immune response that consists of neutralizing antibodies and $\mathrm{T}$ cell responses. Vaccination is associated with long-lived memory responses as well. The strong immune response can enhance antitumor immunity but also limits the ability to provide booster vaccinations in patients with pre-existing antivaccinia immunity.

Vaccinia virus is well characterized as a vaccine and was, in fact, the first vaccine used in humans to prevent smallpox. The low toxicity and effectiveness of the vaccine as a preventive agent has been considerable, in that smallpox has been globally eradicated as a disease. The success of the smallpox eradication program depended on several factors, but notably the potent immunogenicity and safety profile of vaccinia virus and the stability of the virus even at room temperature, which allowed for widespread effective immunization throughout the world. Even though most cancer patients born before 1976 and military personnel have received vaccinia virus as a live smallpox vaccine, the potential for pre-existing immunity against the virus has not posed a serious barrier to either intralesional or systemic delivery of this oncolytic virus to cancer patients previously exposed to the vaccinia vaccine. The large size of the vaccinia genome, the presence of nonessential viral genes, the wide host range, cytoplasmic replication, and vector stability all make vaccinia an attractive virus for expression of recombinant genes. Numerous prokaryotic genes are expressed by vaccinia, which can then be used as a vaccine against microbial organisms harboring the encoded prokaryotic gene products. Expression of eukaryotic genes is also possible, and this has been exploited for cancer therapy by encoding tumor-associated antigens, cytokines, $\mathrm{T}$ cell costimulatory molecules, and other genes under the control of a vaccinia promoter.

\section{Preclinical optimization}

Similar to adenoviruses, deletion of viral virulence genes and functional domains in vaccinia virus can be used to generate tumor-targeting strains of vaccinia with enhanced cell specificity. For example, deletion of the nonessential viral thymidine kinase gene results in selective replication in neoplastic cells. Deletion of other genes, such as vaccinia growth factor, vaccinia type I interferon-binding protein (B18R), double-stranded RNA-binding proteins (E3L), and viral serpins (B13R and B22R), also increase the effectiveness of oncolytic vaccinia viruses by attenuating infection in normal cells and limiting antivaccinia immunity. ${ }^{28}$ The deletion of both viral vaccinia growth factor and thymidine kinase genes further restricts virus replication to malignant cells harboring epidermal growth factor receptor mutations, because vaccinia growth factor depends on the epidermal growth factor receptor to activate thymidine kinase production and induce cellular proliferation. ${ }^{29,30}$ Vaccinia B18R encodes a soluble type I interferon-antagonizing protein that can attenuate viral immunogenicity. Vaccinia with deleted B18R has been shown to confer tumor-selective targeting properties. ${ }^{31-33}$ The full potential of deleting vaccinia genes has not been completely explored, and progress in defining the functional properties of these genes and the potential use of additional viral gene deletions is an area of active investigation. 
Recombinant vaccinia vectors encoding tumor-associated antigens have demonstrated antitumor activity in murine tumor models..$^{34,35} \mathrm{~A}$ new generation of oncolytic vaccinia viruses coexpressing tumor antigens and a variety of proinflammatory cytokines have shown improved therapeutic responses and induction of tumor-specific immunity in animal models and early-phase clinical studies. ${ }^{30,36-38}$ Induction of antitumor immunity is likely aided by oncolytic-mediated cell death and release of tumor antigens and danger signals, such as ATP and high mobility group box-1, into the extracellular microenvironment. ${ }^{39}$ Viral-mediated oncolysis that induces release of these and other immunogenic signature molecules (eg, calreticulin) during cell death can promote an antitumor immune response and be further enhanced by viral expression of immunomodulatory transgenes (eg, GM-CSF). The potential benefit of this approach was initially reported for a recombinant vaccinia virus encoding GM-CSF that abrogated formation of B16 melanoma tumors in mouse models. ${ }^{30,40}$ The role of GM-CSF in promoting proliferation of monocyte-derived suppressor cells suggests that caution may be needed when using GM-CSF to enhance the immunostimulatory properties of vaccinia and other viruses. ${ }^{41}$ However, the strong immune stimulus provided by vaccinia virus and oncolytic cell death induced by infection may allow GM-CSF to induce tumor immunity preferentially when delivered by vaccinia virus. In addition to GM-CSF, other cytokines have been used in recombinant vaccinia vectors, including type I interferons, interleukin (IL)-2, IL-12, and both IL-2 and IL-12. ${ }^{36,42-44}$

Tumor rejection can be dependent on induction of tumor-specific $\mathrm{T}$ cell responses, and another strategy that has been explored is use of vaccinia virus expressing $\mathrm{T}$ cell costimulatory molecules. ${ }^{45} \mathrm{~T}$ cells require two signals for activation: one provided by antigen which is recognized by the $\mathrm{T}$ cell receptor after being processed into smaller peptide fragments and loaded onto a class I or class II major histocompatibility complex molecule for $\mathrm{CD}^{+}$and $\mathrm{CD} 4^{+} \mathrm{T}$ cells, respectively; and the second signal for $\mathrm{T}$ cell activation is provided by $\mathrm{CD} 28$, a $\mathrm{T}$ cell surface receptor that binds to B7.1 and B7.2 found on the surface of antigen-presenting cells. Other costimulatory molecules include 4-1BB, OX40, intercellular adhesion molecule-1, LFA-3, and ICOS, and these have been incorporated into vaccinia viruses in tandem with tumor antigens or alone for an oncolytic vector that can be directly injected into tumors. ${ }^{46,47}$ These vectors have demonstrated significant therapeutic effects, and can induce strong tumor-specific $\mathrm{T}$ cell responses in vivo. As discussed below, this concept has been tested in Phase I clinical trials in which vaccinia virus expressing B7.1 or a triad of costimulatory molecules, including B7.1, intercellular adhesion molecule-1, and LFA-3, was injected into accessible metastatic melanoma lesions. ${ }^{48,49}$

\section{Oncolytic herpes simplex virus Basic virology}

Herpes is derived from the Greek word herpein, meaning "to creep", and describes the creeping or spreading nature of the skin lesions often associated with herpes infection. The herpes family can be subdivided into three major subfamilies that include alpha-herpes, beta-herpes, and gammaherpes viruses, as well as some genera that are not otherwise classified. The alpha-herpes viruses include the simplex and varicella species. These viruses are a major cause of human disease, which generally manifests as skin lesions and rashes. Infection typically occurs in the mucosal surface and results in skin-related vesicular lesions. The viruses can enter peripheral neurons through a process called retrograde axoplasmic flow, where the virus can stay for many years and become reactivated. Lymphocytes and macrophages are also susceptible to herpesvirus infection and may serve as a latent reservoir for viral particles. Herpes simplex virus type 1 is well known as a minor human pathogen and is responsible for the familiar cold sore. The virus consists of three major structural components, ie, a central core where viral DNA sits, a surrounding envelope composed of glycoproteins and host cell membrane fragments, and a capsid. There is an area known as the tegument between the capsid and envelope, containing proteins that are released into infected cells following viral entry. Herpes simplex virus type 1 is a double-stranded DNA virus with a genome size of approximately $152 \mathrm{~kb}$. Viral replication occurs in the nucleus, but insertional mutagenesis does not occur. The large size of the herpes simplex virus type 1 genome, which includes expanses of noncoding regions (approximately $30 \mathrm{~kb}$ nonessential nucleotides), and the lack of insertional mutagenesis makes it an attractive vector for recombinant oncoltytic therapy development.

Herpes simplex virus causes lytic and latent infections, with viral replication generally occurring within 15 hours of exposure. In the lytic phase, the virus typically infects mucosal epithelial cells, with type 1 more common in the oral cavity and mouth, and type 2 more common in the genitalia, although both types may infect any mucosal cells. Epithelial cell entry occurs through binding of viral surface glycoproteins ( $\mathrm{gB}, \mathrm{gC}$, and $\mathrm{gD}$ ) to host cell entry receptors. To date, three entry receptors have been described, including heparan sulfate, herpesvirus entry mediator, and nectins. 
Herpesvirus entry mediator is a member of the tumor necrosis factor superfamily and is highly expressed on natural killer and naïve $\mathrm{CD}^{+} \mathrm{T}$ cells, and can be found at lower levels on $\mathrm{CD}^{+} \mathrm{T}$ cells, dendritic cells, B cells, fibroblasts, and epithelial cells. Nectin-1 and nectin-2 are members of the immunoglobulin superfamily and are found on epithelial cells, neurons, and fibroblasts. Following infection, the mucosal epithelial cell is lysed, releasing progeny viral particles. Latent infection occurs when virions enter sensory neurons, where replication is infrequent because these cells do not divide. During latent infection, latency-associated transcripts are expressed and encode proteins that promote neuron and viral survival, and are needed for reactivation of the viral infection. Reactivation occurs at times of stress and exposure to heat, ultraviolet light, fever, hormonal changes, and nerve trauma. The viral particles travel in an antegrade manner back to the epithelial cells to form the characteristic herpetic lesions. Herpes viruses induce immune responses, and most adults do have evidence of neutralizing antibody titers against herpes simplex virus type 1 .

\section{Preclinical optimization}

Attenuation of virulence and enhancement of the tumor cell-selective properties of herpes simplex virus type 1 have been achieved by deletion of various gene determinants responsible for viral pathogenicity and immunogenicity. Deletion of the gamma-34.5 gene product inhibits the interferon/double-stranded RNA-dependent protein kinase R response mechanism, which naturally impairs host antiviral immunity. In addition, removal of the ICP34.5 gene (the so-called "neurovirulence factor") abrogates the ability of the virus to replicate preferentially in neurons, but is dispensable for its growth in other cells. Given that tumor cells often have a disabled antiviral response pathway, loss of antiviral response genes provides the modified herpesvirus with improved tumor-selective replicative ability. Deletion of the herpes ICP47 gene can improve antigen presentation by major histocompatibility complex class I molecules. The ICP47 gene product normally interferes with the transporter associated with antigen processing machinery and results in downregulation of major histocompatibility complex class I on the surface of cells infected with herpes simplex virus. This helps the virus evade immune detection, and deletion of ICP47 results in increased immunogenicity. Further improvements in oncolytic activity were seen by early expression of the herpes simplex virus unique short 11 (US11) gene, which was placed under an early/immediate, rather than a late, herpes simplex virus promoter. US11 blocks protein kinase
$\mathrm{R}$ phosphorylation and early expression prevents protein kinase $\mathrm{R}$ phosphorylation, which can otherwise be induced by viral transduction and result in more rapid viral clearance. Oncolytic herpes viruses have been developed based on deletion of both the ICP34.5 and ICP47 genes and early expression of US11 to increase tumor selective replication and increase antitumor immunity. Herpes simplex virus tumor selectivity is enhanced further by gain-of-function mutations occurring in given oncogenes of the Ras-signaling pathway of transformed cells, whereby tumor cells with augmented Ras activation are significantly more susceptible to oncolytic herpes simplex virus infection than healthy cells with normal Ras signal transduction pathway physiology. ${ }^{50,51}$

While this vector induces oncolytic-mediated tumor regression, insertion of the gene encoding GM-CSF resulted in rejection of distant noninjected A20 tumors in mice, suggesting the vector could induce potent local oncolytic effects and generate systemic antitumor immunity. ${ }^{52}$ The vector has been further developed, and is completing advancedphase clinical trials for patients with accessible metastatic melanoma.

A barrier to successful use of oncolytic herpes simplex virus is the ubiquitous antiviral response, which limits productive spread and ongoing tumor destruction. Although seropositivity for herpes simplex virus is common and could prevent booster injections, preclinical and clinical data suggest that pre-existing antiherpes antibody titers do not appreciably impact therapeutic responses, which may relate to the intratumoral route of administration. Because local antiviral immunity may limit therapeutic efficacy, strategies to limit local immune response have been used to enhance the oncolytic activity of herpes simplex virus vectors. For example, cyclophosphamide has been used to block bone marrow-derived generation of inflammatory cells prior to administration of herpes simplex virus. ${ }^{53-55}$ Another approach is the use of agents either exogenously administered (eg, cilengitide, bevacizumab) or re-engineered into the virus (eg, vasculostatin) to inhibit vascular permeability or formation of neovasculature in the tumor to limit the extravasation of inflammatory cells into the tumor, and permit enhanced virus production in tumor cells. ${ }^{56,57}$

\section{Oncolytic Newcastle disease virus Basic virology}

Newcastle disease virus (NDV) is an avian paramyxovirus and exists as an enveloped virus that contains a negative-sense double-stranded RNA genome that forms pleiomorphic particles ranging from $150 \mathrm{~nm}$ to $300 \mathrm{~nm}$ in size. Compared with 
other oncolytic viruses, NDV contains a smaller genome slightly larger than $15 \mathrm{~kb}$. NDV enters cells through direct fusion at the plasma membrane or through an endocytic pathway. ${ }^{58}$ The virus replicates in the cytoplasm of infected cells and so does not engage in insertional mutagenesis. ${ }^{59}$ In contrast with oncolytic viruses that have been engineered to target or replicate selectively in tumor cells, NDV maintains a natural preference for cancer cells. ${ }^{60}$ In particular, neoplastic cells that harbor defects in antiviral and apoptotic signaling pathways are highly susceptible to NDV. NDV has also shown a propensity to induce significant antitumor immune responses in patients with advanced cancer. ${ }^{61,62}$ Although NDV causes a fatal illness in most bird populations, it does not cause disease in humans.

\section{Preclinical optimization}

NDV has consistently demonstrated selective replication in tumor cells and this is thought to be related to the lack of capacity of a transformed cell to produce an appropriate interferon response to viral infection. ${ }^{63,64}$ Nontransformed cells thwart NDV infection by establishing an early antiviral response via strong type I interferon responses and a functional interferon-signaling cascade that prevents viral genome amplification. In contrast, tumor cells have a weaker type I interferon response and are unable to halt viral replication. Impairment of crucial antiviral pathways occurring after tumorigenesis appears to be rather common in cancer. ${ }^{63}$ This makes tumor cells highly susceptible to NDV infection and the subsequent oncolytic effects that follow replicative infection; however, due to minimal oncolytic activity, viral modifications to enhance the lytic capabilities of NDV are the subject of current investigation.

Some NDV strains have been developed to elicit potent oncolytic capacity. The MTH-68/H strain showed beneficial effects in patients with advanced cancer. ${ }^{64,65}$ This strain exerts direct cytotoxicity in vitro against various tumor cell lines, suggesting that direct cytotoxicity and oncolysis are key factors in the antitumor activity. NDV-induced apoptosis of infected tumor cells is the dominant mode of cytotoxicity, but activation of either the intrinsic or extrinsic apoptotic pathways is cell type-dependent. ${ }^{66}$ For instance, NDV-mediated cytotoxicity results in the production of tumor necrosis factor- $\alpha$ and tumor necrosis factor-related apoptosis-inducing ligand (TRAIL) in a tumor cell-specific and virus-specific manner, which then leads to activation of caspase $8 .{ }^{66}$ In many tumor cell lines, NDV infection leads to release of cytochrome $\mathrm{C}$ from the mitochondrion and causes activation of caspase 9, a hallmark of the intrinsic pathway. ${ }^{66}$
Overall, activation of the intrinsic apoptotic pathway appears to play a major role in NDV-mediated cell death, but may also involve the extrinsic pathway, the endoplasmic reticulum stress pathway, receptor tyrosine kinase pathways, and/or various other pathways in a cell-dependent manner.

In addition to its direct cytolytic effects, the antitumor activity of NDV is associated with activation of both innate and adaptive immunity. Induction of innate immunity following NDV infection does not depend on viral replication and spread, but rather requires the presence of viral factors. The presence of NDV viral proteins (eg, hemagglutinin-neuraminidase glycoprotein) is sufficient to induce expression of interferon- $\alpha$ and TRAIL by monocytes and natural killer cells, as well as upregulation of enzymes and production of nitric oxide and tumor necrosis factor- $\alpha$ by macrophages. ${ }^{67-70}$ The release of this proinflammatory cytokine mediates the recruitment of natural killer cells, macrophages, and T cells into the tumor microenvironment. Because NDV determinants can indirectly activate early immune cells through diffuse secretion of cytokines, they can also promote antigen-specific antitumor immune responses. Expression of viral hemagglutinin-neuraminidase and F glycoproteins on tumors following NDV infection leads to upregulation of $\mathrm{T}$ cell activation markers; expression of hemagglutinin-neuraminidase on antigen-presenting cells has been shown to augment cytotoxic $\mathrm{T}$ lymphocyte responses against infected tumor. ${ }^{71-74}$ These findings imply that NDV infection may overcome the suppressive effects of the tumor microenvironment and induce favorable proinflammatory antitumor responses. The important role of immunomodulatory cytokines during NDV infection of tumors in culture and in vivo have led to recombinant NDV vectors engineered to express cytokines to enhance local antitumor activity. ${ }^{75}$ Other approaches have tried to enhance the intrinsic cytolytic properties of NDV via increased expression of native viral proapoptotic proteins (eg, F protein), inhibition of innate immune responses for enhancement of viral replication and cell-to-cell spread, tumor-associated antigens, and immunostimulatory cytokines (eg, GM-CSF, IL-2, and tumor necrosis factor- $\alpha){ }^{75}$

The importance of the immune response with oncolytic NDV vectors has been highlighted in murine tumor models. ${ }^{76}$ Therapeutic activity can be seen with only a small dose of injected NDV, suggesting that therapeutic responses are not completely dependent on the oncolytic activity of the virus. ${ }^{77}$ Further support for immune responses include the observation that infected tumor cells have the ability to be processed by dendritic cells, which can then prime T cells for activation of 
an antitumor response. ${ }^{78}$ Further, these NDV-initiated immunogenic effects are stronger when the virus is applied locally compared with systemic administration. ${ }^{79,80}$ Oncolysates derived from tumor cells infected with the nonlytic Ulster strain of NDV have been used as an autologous tumor vaccine, known as ATV-NDV. ${ }^{76,78}$ The release of danger signals due to the presence of double-stranded RNA, activation of $\mathrm{T}$ cell costimulatory molecules by the NDV attachment protein, hemagglutinin-neuraminidase, and upregulation of major histocompatibility complex class I, and cell adhesion molecules on tumor cells can induce antigen-specific $\mathrm{T}$ cell responses. NDV-mediated immunogenicity promotes expression of type I interferons and chemokines, such as RANTES and interferon gamma-inducible protein 10, to activate further the host immune response against the tumor. ${ }^{81-83}$ These potent immune-activating features of ATV-NDV are able to activate pre-existing antitumor and memory $\mathrm{T}$ cell responses, and this has been confirmed by delayed-type hypersensitivity responses following oncolytic infection. ${ }^{78}$

\section{Oncolytic coxsackie virus Basic virology}

Coxsackie virus is an enterovirus belonging to the Picornaviridæ family of nonenveloped viruses containing a linear, positive sense, single-stranded RNA genome. Because RNA viruses replicate in the host cytosol without a DNA phase, insertional mutagenesis is not possible. Coxsackie viruses are divided into two subgroups, A and B, based on pathogenicity in mice. At least 23 serotypes of group A and six serotypes of group B have been described. Coxsackie viruses are considered to be a minor human pathogen. Young children, aged five years and under, are more susceptible to coxsackie virus A disease, often produced by serotype A16. Infection of individuals occurs mainly via entry through exposed areas, such as the skin and mucosal surfaces (ie, hands, feet, mouth, throat, and eyes). However, in most cases, infection is asymptomatic or elicits only mild disease associated with "common cold-like" symptoms. ${ }^{84-86}$ Various nonengineered strains of coxsackie virus from both groups are currently being tested as single oncolytic therapeutics or in combination with conventional chemotherapy drugs.

\section{Preclinical optimization}

In preclinical models, coxsackie virus B3 (CVB3) exhibited potent tumor cell lysis in a number of non-small cell lung cancer cell lines, even in cancer cells refractory to conventional radiotherapy and molecular targeted therapies. ${ }^{87}$ Furthermore, deployment of coxsackie viruses into the local tumor environment induced productive cell spread and promoted immunogenic cytotoxicity following tumor oncolysis. CVB3 infection elicited immunogenic changes in cancer cells associated with the release of extracellular ATP, exposure of calreticulin at the cell surface, and high mobility group box-1 translocation. ${ }^{87}$ These hallmark immunostimulatory markers can alter the repertoire of immune cells within the tumor microenvironment to promote immune-mediated tumor rejection. ${ }^{88}$ Recruitment of innate immune cells associated with direct lysis of tumor cells and priming of adaptive immunity was seen, including an accumulation of activated natural killer cells and immunogenic dendritic cells. ${ }^{89,90}$

CVB3 was shown to convert dysfunctional dendritic cells into functional dendritic cells after ligation of retinoic acid-inducible gene-1-like receptors with the single-stranded RNA genome of coxsackie virus. ${ }^{91}$ The virus could also activate neutrophils to release interferon- $\beta$ and antigenpresenting cells and to induce cytotoxic T lymphocytes. ${ }^{92,93}$ These immunostimulatory features of coxsackie virus in innate and adaptive immunity suggest that coxsackie viruses may be able to synergize its immunogenic effects with its direct oncolytic activities to promote tumor regression. CVA21, a native coxsackie virus vector that differs from CVB3 in the surface viral receptors it targets for adhesion, entry, and lytic infection, is currently in clinical trials, as described below.

\section{Oncolytic reovirus Basic virology}

Reovirus (respiratory enteric orphan virus) is a naturally occurring, nonenveloped double-stranded RNA virus that is nonpathogenic in humans. The virus possesses potent oncolytic activity in various human tumor cells. While reovirus binds to ubiquitously expressed sialic acid on mammalian cells and is internalized, reovirus replicates only in tumors with a constitutively activated Ras-pathway. ${ }^{94}$ Further, the deregulated Ras signal transduction pathway in tumor cells leads to inhibition of protein kinase $\mathrm{R}$ autophosphorylation, which is a downstream effector molecule of the interferon signaling pathway and plays a major role in the host antiviral response. Protein kinase $\mathrm{R}$ inhibition precludes phosphorylation of the $\alpha$-subunit of the translation initiation factor, which necessitates viral gene translation and would otherwise protect a normal cell from reovirus-mediated lysis. The abrogated viral defense pathway in numerous tumor cells permits productive cell-to-cell spread of reovirus progeny with high infectious capacity. For example, enhanced Ras signaling in 
cancer cells: provides a favorable cellular environment that upregulates cathepsin lysosomal proteases to aid in reovirus uncoating and processing; facilitates post-translational modification of viral proteins and their assembly into virions; and engenders viral spread because of augmented susceptibility of the transformed cell to reovirus-induced apoptosis at later stages of infection. ${ }^{95-99}$ With approximately half of known malignancies expressing a gain-of-function mutation in the Ras pathway, reovirus has been shown to be an ideal oncolytic agent against many different types of neoplastic cells. ${ }^{100-103}$ The oncotropism and specific cytopathic effect of reovirus in Ras-transformed cells combined with its benign virulence in normal human tissues make reovirus a suitable candidate for oncolytic virus therapy, and may be more amenable to systemic delivery.

\section{Preclinical optimization}

Reovirus is inherently tumor-selective and has demonstrated negligible pathogenicity in vivo. Over the past decade, the preclinical efficacy of reovirus in treating multiple tumor types has been reported. Regression of a number of human cancer types, including colorectal, ovarian, brain, breast, bladder, pancreatic, prostate, and hematological malignancies, has been observed following the administration of a single intratumoral reovirus injection $\left(1 \times 10^{7}\right.$ plaque-forming units) in SCID/NOD murine xenograft models. ${ }^{100,101,104-107}$ Reovirus oncolysis of cancer cells is mediated mainly via the extrinsic apoptosis pathway. ${ }^{108-112}$ Depending on the tumor cell infected, reovirus-induced apoptosis uses different proapoptotic molecules to activate apoptosis. For example, the HeLa cell line requires NF- $\mathrm{KB}$ for apoptosis, while specific ovarian, breast, and lung cancer cell lines activate apoptosis via sensitization to TRAIL and activation of the death receptor pathway of apoptosis. ${ }^{108-110}$ The oncolytic efficacy in preclinical studies has led to several Phase I/II and Phase III clinical trials discussed below. Reovirus, like other oncolytic vectors, is subject to immune recognition and rapid clearance. Use of immunosuppressant drugs, such as cyclophosphamide and cyclosporine A, has been shown to potentiate oncolysis and increase reovirus replication in injected tumor tissue with enhanced reovirus-mediated tumor clearance. ${ }^{113}$

\section{Clinical results of oncolytic virus therapy}

Clinical development of oncolytic virus therapy began over a century ago and, since then, numerous trials have been initiated to treat hundreds of cancer patients with a variety of native, modified, and recombinant oncolytic viruses. ${ }^{114}$ Overall, oncolytic virus therapy has been well tolerated, with largely minor and expected toxicity, and no evidence of uncontrolled or latent infection, household transmission, or malignant transformation. ${ }^{114,115}$ A number of clinical trials have combined oncolytic viruses with a second form of therapy. These trials include widely used chemotherapeutics, such as cisplatin or radiation, and these trials have shown a high frequency of clinical responses. ${ }^{114}$ However, interpretation of these studies is hampered by the lack of randomized study designs and lack of more appropriate clinical endpoints, such as progression-free or overall survival. Table 2 lists current studies of oncolytic viruses for cancer, and we now describe in detail several of the more promising clinical trials.

JX-594 is an oncolytic, thymidine kinase-deleted vaccinia virus based on the Wyeth strain (Jennerex Biotherapeutics, San Francisco, CA, USA) that was engineered to express GM-CSF and LacZ (which encodes beta-galactosidase). The vector has shown promising clinical responses when delivered by intratumorally and systemically. ${ }^{38,40,116-118}$ Treatment with JX-594 induced antitumor immunity, as evidenced by regression of distant uninjected lesions, and appearance of tumor-infiltrating eosinophils, T cells, B cells, and macrophages in injected lesions. Further studies have suggested that the oncolytic activity and transgene expression of JX-594 are highly selective and mediated via several mechanisms, including activation of replication by epidermal growth factor receptor and Ras signaling, cellular thymidine kinase levels, and an abnormal interferon response in tumor cells. ${ }^{119}$

An oncolytic herpes simplex virus-1 vector with an ICP34.5 and ICP47 deletion and encoding human GM-CSF has yielded highly encouraging clinical data in Phase I and II clinical melanoma trials. The vector has been named talimogene laherparepvec (TVEC, Amgen Inc., Sherman Oaks, CA, USA). The safety of this vector has been established in Phase I and II trials where a treatment regimen consisting of intratumoral injection of accessible, metastatic melanoma lesions resulted in mild fever and flu-like symptoms and injection site reactions, generally all low grade. In a multiinstitutional Phase II clinical trial, TVEC induced an objective clinical response in $28 \%$ of patients, and this included regression of both injected and noninjected lesions. ${ }^{120}$ Oncolytic virotherapy was associated with development of peripheral and tumor-infiltrating MART-1-specific CD ${ }^{+}$ $\mathrm{T}$ cell responses and a decrease in $\mathrm{CD} 4^{+} \mathrm{FoxP} 3^{+}$regulatory $\mathrm{T}$ cells and monocyte-derived suppressor cells in the tumor microenvironment. Similar patterns of response were seen at distant noninjected lesions, but at a lower frequency, 
suggesting that local oncolytic viral injections were able to induce melanoma-specific systemic immunity. Based on these results, an international, prospective, randomized clinical trial was conducted in which 460 patients with advanced melanoma were randomized in a 2:1 manner to treatment with TVEC or recombinant GM-CSF. The trial was closed to accrual in June 2011 and initial results are expected in 2013. A Phase II trial to combine TVEC with the anticytotoxic T lymphocyte A-4 monoclonal antibody, ipilimumab, is planned.

NDV was used to infect irradiated, autologous tumor cells to generate a vaccine (ATV-NDV) for the treatment of patients with advanced colorectal cancer. In this nonrandomized Phase II study, patients with Duke's B or C colorectal cancer with enough tumor cells available for vaccination were randomized to NDV-infected cells or BCG-infected cells. An improvement in survival was reported for patients receiving the ATV-NDV vaccine. ${ }^{121}$ Other early-phase clinical trials with this vaccine have been reported in patients with breast cancer, colorectal cancer, glioblastoma, and head and neck squamous cell carcinoma. ${ }^{122,123}$ A clinical trial utilizing the ATV-NDC vaccine combined with bispecific monoclonal antibodies that function as CD3 and CD28 agonists at the tumor site demonstrated significant antitumor activity. ${ }^{76,124}$ Further trials with NDV have evaluated combinations with low-dose IL-2 and interferon- $\alpha$. Clinical studies demonstrate that adjuvant vaccination with autologous NDV-modified cancer cells is safe and appears to confer extended benefit in uncontrolled studies; however, further prospective and randomized clinical trials will be needed to define the role of NDV vaccination in cancer.

Coxsackie virus A21 (CVA21, Cavatak ${ }^{\mathrm{TM}}$, Viralytics, Sydney, Australia) exhibits potent oncolytic activity both in vitro and in vivo against a number of human cancers, including melanoma, multiple myeloma, breast cancer, prostate cancer, and malignant glioma. ${ }^{125-128}$ Cavatak has completed Phase I clinical evaluation in patients with advanced stage melanoma, breast cancer, prostate cancer, and head and neck cancer. ${ }^{125-128}$ CVA21 tumor tropism of susceptible cells requires interaction between CVA21 and intercellular adhesion molecule-1, along with a secondary receptor, decay-accelerating factor, for cellular entry and infection of CVA21 in cancer cells. ${ }^{125-128}$ These CVA21 entry molecules are commonly unregulated on the surface of many cancer cells. Their high expression levels on tumors serve as suitable receptors for cancer selectivity of the virus and are positively correlated with coxsackie virus-induced oncolytic activity. ${ }^{129}$ A potential barrier to effective therapy is the existence of pre- existing immunity against the native virus. However, in one small clinical trial, only a few patients (three of 21) exhibited low anti-CVA21-protective antibody titers. ${ }^{130}$ Serum from individuals who were seropositive for CVA21 failed to show cross-neutralization to other group A coxsackie viruses, ie, A13, A15, or A18. ${ }^{130}$ Thus, prime-boost strategies utilizing alternate strains of coxsackie A virus might be one approach to increase antitumor immunity and therapeutic responses with oncolytic coxsackie viruses. ${ }^{130}$

Sixteen Phase I and Phase II studies of Reolysin ${ }^{\circledR}$, a native reovirus, injected intralesionally or systemically, have been or are currently being conducted in adult patients with central nervous system and extracranial solid tumors. ${ }^{103}$ The virus is being tested as a monotherapy or in combination with chemotherapy or radiation therapy. Objective responses and disease stabilization have been reported, with few side effects, ranging from flu-like symptoms to mild gastrointestinal symptoms to neutropenia. Phase I dose-escalation studies using intravenous administration as monotherapy or combined with chemotherapy, including gemcitabine, docetaxel, and carboplatin/paclitaxel, or combined with radiotherapy, have been completed. To date, over 100 patients have been treated with Reolysin, and severe dose-limiting toxicities have not been reported. While the oncolytic virus is well tolerated in patients and local responses were seen in patients with melanoma, head and neck cancer, and Kaposi's sarcoma, evidence for antitumor efficacy at distant sites was not seen. The presence of neutralizing antireovius antibody titers associated with the dose of Reolysin administered elicited immune clearance of the reovirus and may have limited its systemic efficacy.

\section{Summary}

The clinical utility of oncolytic viruses is often based on their capacity to infect selectively and replicate in tumor cells. The potential clinical utility may be enhanced by viral modification to express transgenes that can augment the oncolytic or immune-potentiating capability of the virus. A variety of viral vectors have been utilized, including adenovirus, vaccinia virus, herpesvirus, Newcastle disease virus, coxsackie virus, and reovirus. These viruses offer distinct advantages and disadvantages (reviewed in Table 1). The transformed state of tumor cells induces attenuated antiviral defenses, and therefore provides a favorable niche in which oncolytic viruses can productively replicate and induce cell death. This tumor-selective property of oncolytic viruses is made possible through deletion of viral virulence genes or functional domains that effectively attenuate the ability of the virus to 
infect and lyse normal cells productively without diminishing their tumor infectivity. Additional therapeutic effects appear to be related to induction of an antitumor immune response. Clinical development of several oncolytic viruses, including JX-594 and TVEC, are in late-stage development. Barriers to effective clinical use of oncolytic viruses remain, with induction of antivirus-neutralizing antibody a potential problem with most vectors. Although several clinically utilized viruses have the potential for minor toxicity and transmission to close contacts, to date there have been minimal reports of patient adverse events and no significant environmental exposure events.

\section{Future directions}

Significant progress has been made in the development of oncolytic viruses as a cancer therapy in the last few years. Improved tumor cell targeting and methods for enhancing the antitumor immune response have been particularly useful for increasing the therapeutic potency of oncolytic viruses. A better understanding of the functional roles of various viral genes has aided the modification of oncolytic viruses to alter tumor selectivity, pathogenicity, and immunogenicity, and to optimize the clinical potential of these vectors. Further investigation will need to focus on optimal selection of viruses, tumor types and stages of disease, viral dose and schedules, routes of delivery, and identifying potential combinations that may enhance or add to the pharmacological mechanisms of action for these unique vectors. The outcome of several large prospective trials, particularly those using JX-594 and TVEC, will provide important insights into the true clinical potential of oncolytic viruses in patients with advanced cancer. Although this is an emerging field, it is worthwhile to note that the safety profile for oncolytic viruses has been acceptable with most treatment being easily accomplished in the outpatient setting with minimal serious adverse events reported. Oncolytic viruses represent a highly targeted approach to established cancer that brings a multimechanistic approach and an acceptable safety profile to patients with a variety of cancers. The next few years will likely be exciting with the completion of several large randomized clinical trials and additional refinements in vector design and combination therapy.

\section{Disclosure}

The authors report no conflicts of interest in this work.

\section{References}

1. Xia ZJ, Chang JH, Zhang L, et al. Phase III randomized clinical trial of intratumoral injection of E1B gene-deleted adenovirus (H101) combined with cisplatin-based chemotherapy in treating squamous cell cancer of head and neck or esophagus. Ai Zheng. 2004;23(12):1666-1670. Chinese.
2. Yamamoto M, Curiel DT. Cancer gene therapy. Technol Cancer Res Treat. 2005;4(4):315-330.

3. Huebner RJ, Rowe WP, Schatten WE, Smith RR, Thomas LB. Studies on the use of viruses in the treatment of carcinoma of the cervix. Cancer. 1956;9(6):1211-1218.

4. Gaggar A, Shayakhmetov DM, Liszewski MK, Atkinson JP, Lieber A Localization of regions in CD46 that interact with adenovirus. $J$ Virol. 2005;79(12):7503-7513.

5. Sirena D, Lilienfeld B, Eisenhut M, et al. The human membrane cofactor CD46 is a receptor for species B adenovirus serotype 3. $J$ Virol. 2004;78(9):4454-4462.

6. Krasnykh V, Dmitriev I, Mikheeva G, Miller CR, Belousova N, Curiel DT. Characterization of an adenovirus vector containing a heterologous peptide epitope in the HI loop of the fiber knob. $J$ Virol. 1998;72(3):1844-1852.

7. Dmitriev I, Kashentseva E, Rogers BE, Krasnykh V, Curiel DT. Ectodomain of coxsackievirus and adenovirus receptor genetically fused to epidermal growth factor mediates adenovirus targeting to epidermal growth factor receptor-positive cells. J Virol. 2000;74(15): 6875-6884.

8. Yamamoto M, Davydova J, Wang M, et al. Infectivity enhanced, cyclooxygenase-2 promoter-based conditionally replicative adenovirus for pancreatic cancer. Gastroenterology. 2003;125(4):1203-1218.

9. Takayama K, Reynolds PN, Short JJ, et al. A mosaic adenovirus possessing serotype Ad5 and serotype Ad3 knobs exhibits expanded tropism. Virology. 2003;309(2):282-293.

10. Douglas JT, Rogers BE, Rosenfeld ME, Michael SI, Feng M, Curiel DT. Targeted gene delivery by tropism-modified adenoviral vectors. Nat Biotechnol. 1996;14(11):1574-1578.

11. Curiel DT. Strategies to adapt adenoviral vectors for targeted delivery. Ann N Y Acad Sci. 1999;886:158-171.

12. Tanaka T, Huang J, Hirai S, et al. Carcinoembryonic antigen-targeted selective gene therapy for gastric cancer through FZ33 fiber-modified adenovirus vectors. Clin Cancer Res. 2006;12(12):3803-3813.

13. Li HJ, Everts M, Yamamoto M, Curiel DT, Herschman HR. Combined transductional untargeting/retargeting and transcriptional restriction enhances adenovirus gene targeting and therapy for hepatic colorectal cancer tumors. Cancer Res. 2009;69(2):554-564.

14. Bischoff JR, Kirn DH, Williams A, et al. An adenovirus mutant that replicates selectively in p53-deficient human tumor cells. Science. 1996;274(5286):373-376.

15. Heise C, Sampson-Johannes A, Williams A, McCormick F, Von Hoff DD, Kirn DH. ONYX-015, an E1B gene-attenuated adenovirus, causes tumor-specific cytolysis and antitumoral efficacy that can be augmented by standard chemotherapeutic agents. Nat Med. 1997;3(6):639-645.

16. Marx J. Oncology. Recruiting the cell's own guardian for cancer therapy. Science. 2007;315(5816):1211-1213.

17. O'Shea CC, Johnson L, Bagus B, et al. Late viral RNA export, rather than 553 inactivation, determines ONYX-015 tumor selectivity. Cancer Cell. 2004;6(6):611-623.

18. Rodriguez R, Schuur ER, Lim HY, Henderson GA, Simons JW, Henderson DR. Prostate attenuated replication competent adenovirus (ARCA) CN706: a selective cytotoxic for prostate-specific antigen-positive prostate cancer cells. Cancer Res. 1997;57(13): $2559-2563$.

19. Alemany R, Balague C, Curiel DT. Replicative adenoviruses for cancer therapy. Nat Biotechnol. 2000;18(7):723-727.

20. Curiel DT. The development of conditionally replicative adenoviruses for cancer therapy. Clin Cancer Res. 2000;6(9):3395-3399.

21. Guedan S, Rojas JJ, Gros A, Mercade E, Cascallo M, Alemany R. Hyaluronidase expression by an oncolytic adenovirus enhances its intratumoral spread and suppresses tumor growth. Mol Ther. 2010;18(7): $1275-1283$.

22. Jin F, Xie Z, Kuo CJ, Chung LW, Hsieh CL. Cotargeting tumor and tumor endothelium effectively inhibits the growth of human prostate cancer in adenovirus-mediated antiangiogenesis and oncolysis combination therapy. Cancer Gene Ther. 2005;12(3):257-267. 
23. Gupta V, Wang W, Sosnowski BA, Hofman FM, Chen TC. Fibroblast growth factor-2-retargeted adenoviral vector for selective transduction of primary glioblastoma multiforme endothelial cells. Neurosurg Focus. 2006;20(4):E26.

24. Seth P, Wang ZG, Pister A, et al. Development of oncolytic adenovirus armed with a fusion of soluble transforming growth factor-beta receptor II and human immunoglobulin Fc for breast cancer therapy. Hum Gene Ther. 2006;17(11):1152-1160.

25. Shashkova EV, Kuppuswamy MN, Wold WS, Doronin K. Anticancer activity of oncolytic adenovirus vector armed with IFN-alpha and ADP is enhanced by pharmacologically controlled expression of TRAIL. Cancer Gene Ther. 2008;15(2):61-72.

26. Green NK, Herbert CW, Hale SJ, et al. Extended plasma circulation time and decreased toxicity of polymer-coated adenovirus. Gene Ther. 2004;11(16):1256-1263.

27. Doronin K, Shashkova EV, May SM, Hofherr SE, Barry MA. Chemical modification with high molecular weight polyethylene glycol reduces transduction of hepatocytes and increases efficacy of intravenously delivered oncolytic adenovirus. Hum Gene Ther. 2009;20(9):975-988.

28. Hengstschlager M, Knofler M, Mullner EW, Ogris E, Wintersberger E, Wawra E. Different regulation of thymidine kinase during the cell cycle of normal versus DNA tumor virus-transformed cells. J Biol Chem. 1994;269(19):13836-13842.

29. McCart JA, Ward JM, Lee J, et al. Systemic cancer therapy with a tumor-selective vaccinia virus mutant lacking thymidine kinase and vaccinia growth factor genes. Cancer Res. 2001;61(24):8751-8757.

30. Thorne SH, Hwang TH, O'Gorman WE, et al. Rational strain selection and engineering creates a broad-spectrum, systemically effective oncolytic poxvirus, JX-963. J Clin Invest. 2007;117(11):3350-3358.

31. Colamonici OR, Domanski P, Sweitzer SM, Larner A, Buller RM. Vaccinia virus B18R gene encodes a type I interferon-binding protein that blocks interferon alpha transmembrane signaling. $J$ Biol Chem. 1995;270(27):15974-15978.

32. Kim JH, Lee YS, Kim H, Huang JH, Yoon AR, Yun CO. Relaxin expression from tumor-targeting adenoviruses and its intratumoral spread, apoptosis induction, and efficacy. $J$ Natl Cancer Inst. 2006;98(20): $1482-1493$

33. Symons JA, Alcami A, Smith GL. Vaccinia virus encodes a soluble type I interferon receptor of novel structure and broad species specificity. Cell. 1995;81(4):551-560.

34. Kirn DH, Thorne SH. Targeted and armed oncolytic poxviruses: a novel multi-mechanistic therapeutic class for cancer. Nat Rev Cancer. 2009;9(1):64-71.

35. Thorne SH, Hwang TH, Kirn DH. Vaccinia virus and oncolytic virotherapy of cancer. Curr Opin Mol Ther. 2005;7(4):359-365.

36. Kirn DH, Wang Y, Le Boeuf F, Bell J, Thorne SH. Targeting of interferon-beta to produce a specific, multi-mechanistic oncolytic vaccinia virus. PLoS Med. 2007;4(12):e353.

37. Liu TC, Hwang T, Park BH, Bell J, Kirn DH. The targeted oncolytic poxvirus JX-594 demonstrates antitumoral, antivascular, and antiHBV activities in patients with hepatocellular carcinoma. Mol Ther. 2008;16(9):1637-1642.

38. Park BH, Hwang T, Liu TC, et al. Use of a targeted oncolytic poxvirus, JX-594, in patients with refractory primary or metastatic liver cancer: a phase I trial. Lancet Oncol. 2008;9(6):533-542.

39. Guo ZS, Naik A, O'Malley ME, et al. The enhanced tumor selectivity of an oncolytic vaccinia lacking the host range and antiapoptosis genes SPI-1 and SPI-2. Cancer Res. 2005;65(21):9991-9998.

40. Dranoff G, Jaffee E, Lazenby A, et al. Vaccination with irradiated tumor cells engineered to secrete murine granulocyte-macrophage colonystimulating factor stimulates potent, specific, and long-lasting antitumor immunity. Proc Natl Acad Sci U S A. 1993;90(8):3539-3543.

41. Filipazzi P, Valenti R, Huber V, et al. Identification of a new subset of myeloid suppressor cells in peripheral blood of melanoma patients with modulation by a granulocyte-macrophage colony-stimulation factorbased antitumor vaccine. J Clin Oncol. 2007;25(18): 2546-2553.
42. Bronte V, Tsung K, Rao JB, et al. IL-2 enhances the function of recombinant poxvirus-based vaccines in the treatment of established pulmonary metastases. J Immunol. 1995;154(10):5282-5292.

43. Rao JB, Chamberlain RS, Bronte V, et al. IL-12 is an effective adjuvant to recombinant vaccinia virus-based tumor vaccines: enhancement by simultaneous B7-1 expression. J Immunol. 1996;156(9):3357-3365.

44. Kaufman HL, Flanagan K, Lee CS, Perretta DJ, Horig H. Insertion of interleukin-2 (IL-2) and interleukin-12 (IL-12) genes into vaccinia virus results in effective anti-tumor responses without toxicity. Vaccine. 2002;20(13-14):1862-1869.

45. Hodge JW, Sabzevari H, Yafal AG, Gritz L, Lorenz MG, Schlom J. A triad of costimulatory molecules synergize to amplify T-cell activation. Cancer Res. 1999;59(22):5800-5807.

46. Hodge JW, Higgins J, Schlom J. Harnessing the unique local immunostimulatory properties of modified vaccinia Ankara (MVA) virus to generate superior tumor-specific immune responses and antitumor activity in a diversified prime and boost vaccine regimen. Vaccine. 2009;27(33):4475-4482.

47. Kudo-Saito C, Hodge JW, Kwak H, Kim-Schulze S, Schlom J, Kaufman HL. 4-1BB ligand enhances tumor-specific immunity of poxvirus vaccines. Vaccine. 2006;24(23):4975-4986.

48. Kaufman HL, Deraffele G, Mitcham J, et al. Targeting the local tumor microenvironment with vaccinia virus expressing B7.1 for the treatment of melanoma. J Clin Invest. 2005;115(7):1903-1912.

49. Kaufman HL, Cohen S, Cheung K, et al. Local delivery of vaccinia virus expressing multiple costimulatory molecules for the treatment of established tumors. Hum Gene Ther. 2006;17(2):239-244.

50. Farassati F, Yang AD, Lee PW. Oncogenes in Ras signalling pathway dictate host-cell permissiveness to herpes simplex virus 1. Nat Cell Biol. 2001;3(8):745-750.

51. Pan W, Bodempudi V, Esfandyari T, Farassati F. Utilizing ras signaling pathway to direct selective replication of herpes simplex virus-1. PLoS One. 2009;4(8):e6514.

52. Liu BL, Robinson M, Han ZQ, et al. ICP34.5 deleted herpes simplex virus with enhanced oncolytic, immune stimulating, and anti-tumour properties. Gene Ther. 2003;10(4):292-303.

53. Ikeda $\mathrm{K}$, Ichikawa $\mathrm{T}$, Wakimoto $\mathrm{H}$, et al. Oncolytic virus therapy of multiple tumors in the brain requires suppression of innate and elicited antiviral responses. Nat Med. 1999;5(8):881-887.

54. Currier MA, Gillespie RA, Sawtell NM, et al. Efficacy and safety of the oncolytic herpes simplex virus rRp450 alone and combined with cyclophosphamide. Mol Ther. 2008;16(5):879-885.

55. Fulci G, Breymann L, Gianni D, et al. Cyclophosphamide enhances glioma virotherapy by inhibiting innate immune responses. Proc Natl Acad Sci U S A. 2006;103(34):12873-12878.

56. Kaur B, Brat DJ, Devi NS, Van Meir EG. Vasculostatin, a proteolytic fragment of brain angiogenesis inhibitor 1, is an antiangiogenic and antitumorigenic factor. Oncogene. 2005;24(22):3632-3642.

57. Kurozumi K, Hardcastle J, Thakur R, et al. Oncolytic HSV-1 infection of tumors induces angiogenesis and upregulates CYR61. Mol Ther. 2008;16(8):1382-1391.

58. Cantin C, Holguera J, Ferreira L, Villar E, Munoz-Barroso I. Newcastle disease virus may enter cells by caveolae-mediated endocytosis. $J$ Gen Virol. 2007;88(Pt 2):559-569.

59. Kelly EJ, Hadac EM, Greiner S, Russell SJ. Engineering microRNA responsiveness to decrease virus pathogenicity. Nat Med. 2008;14(11): $1278-1283$.

60. Fiola C, Peeters B, Fournier P, Arnold A, Bucur M, Schirrmacher V. Tumor selective replication of Newcastle disease virus: association with defects of tumor cells in antiviral defence. Int J Cancer. 2006;119(2):328-338.

61. Schirrmacher V, Haas C, Bonifer R, Ahlert T, Gerhards R, Ertel C. Human tumor cell modification by virus infection: an efficient and safe way to produce cancer vaccine with pleiotropic immune stimulatory properties when using Newcastle disease virus. Gene Ther. 1999;6(1): 63-73.

62. Apostolidis L, Schirrmacher V, Fournier P. Host mediated antitumor effect of oncolytic Newcastle disease virus after locoregional application. Int J Oncol. 2007;31(5):1009-1019. 
63. Wilden H, Fournier P, Zawatzky R, Schirrmacher V. Expression of RIGI, IRF3, IFN-beta and IRF7 determines resistance or susceptibility of cells to infection by Newcastle disease virus. Int J Oncol. 2009;34(4): 971-982.

64. Csatary LK, Gosztonyi G, Szeberenyi J, et al. MTH-68/H oncolytic viral treatment in human high-grade gliomas. J Neurooncol. 2004;67(1-2): 83-93.

65. Csatary LK, Bakacs T. Use of Newcastle disease virus vaccine (MTH$68 / \mathrm{H})$ in a patient with high-grade glioblastoma. JAMA. 1999;281(17): 1588-1589.

66. Elankumaran S, Rockemann D, Samal SK. Newcastle disease virus exerts oncolysis by both intrinsic and extrinsic caspase-dependent pathways of cell death. J Virol. 2006;80(15):7522-7534.

67. Hrabak A, Csuka I, Bajor T, Csatary LK. The cytotoxic anti-tumor effect of MTH-68/H, a live attenuated Newcastle disease virus is mediated by the induction of nitric oxide synthesis in rat peritoneal macrophages in vitro. Cancer Lett. 2006;231(2):279-289.

68. Lorence RM, Rood PA, Kelley KW. Newcastle disease virus as an antineoplastic agent: induction of tumor necrosis factor-alpha and augmentation of its cytotoxicity. J Natl Cancer Inst. 1988;80(16):1305-1312.

69. Schirrmacher V, Bai L, Umansky V, Yu L, Xing Y, Qian Z. Newcastle disease virus activates macrophages for anti-tumor activity. Int J Oncol. 2000;16(2):363-373.

70. Umansky V, Shatrov VA, Lehmann V, Schirrmacher V. Induction of NO synthesis in macrophages by Newcastle disease virus is associated with activation of nuclear factor-kappa B. Int Immunol. 1996;8(4): 491-498.

71. de Leeuw OS, Koch G, Hartog L, Ravenshorst N, Peeters BP. Virulence of Newcastle disease virus is determined by the cleavage site of the fusion protein and by both the stem region and globular head of the haemagglutinin-neuraminidase protein. J Gen Virol. 2005;86(Pt 6): 1759-1769.

72. Huang Z, Panda A, Elankumaran S, Govindarajan D, Rockemann DD, Samal SK. The hemagglutinin-neuraminidase protein of Newcastle disease virus determines tropism and virulence. $J$ Virol. 2004;78(8): 4176-4184.

73. Kim SH, Subbiah M, Samuel AS, Collins PL, Samal SK. Roles of the fusion and hemagglutinin-neuraminidase proteins in replication, tropism, and pathogenicity of avian paramyxoviruses. J Virol. 2011; 85(17):8582-8596.

74. Romer-Oberdorfer A, Veits J, Werner O, Mettenleiter TC. Enhancement of pathogenicity of Newcastle disease virus by alteration of specific amino acid residues in the surface glycoproteins F and HN. Avian Dis. 2006;50(2):259-263.

75. Zamarin D, Palese P. Oncolytic Newcastle disease virus for cancer therapy: old challenges and new directions. Future Microbiol. 2012; 7(3):347-367.

76. Fournier P, Bian H, Szeberenyi J, Schirrmacher V. Analysis of three properties of Newcastle disease virus for fighting cancer: tumor-selective replication, antitumor cytotoxicity, and immunostimulation. Methods Mol Biol. 2012;797:177-204.

77. Bian H, Wilden H, Fournier P, Peeters B, Schirrmacher V. In vivo efficacy of systemic tumor targeting of a viral RNA vector with oncolytic properties using a bispecific adapter protein. Int J Oncol. 2006;29(6): 1359-1369.

78. Bai L, Koopmann J, Fiola C, Fournier P, Schirrmacher V. Dendritic cells pulsed with viral oncolysates potently stimulate autologous $\mathrm{T}$ cells from cancer patients. Int J Oncol. 2002;21(4):685-694.

79. Phuangsab A, Lorence RM, Reichard KW, Peeples ME, Walter RJ. Newcastle disease virus therapy of human tumor xenografts: antitumor effects of local or systemic administration. Cancer Lett. 2001;172(1): 27-36.

80. Schirrmacher V, Griesbach A, Ahlert T. Antitumor effects of Newcastle disease virus in vivo: local versus systemic effects. Int $J$ Oncol. 2001;18(5):945-952

81. Fournier P, Zeng J, Schirrmacher V. Two ways to induce innate immune responses in human PBMCs: paracrine stimulation of IFNalpha responses by viral protein or dsRNA. Int J Oncol. 2003;23(3): 673-680.
82. Washburn B, Schirrmacher V. Human tumor cell infection by Newcastle disease virus leads to upregulation of HLA and cell adhesion molecules and to induction of interferons, chemokines and finally apoptosis. Int J Oncol. 2002;21(1):85-93.

83. Washburn B, Weigand MA, Grosse-Wilde A, et al. TNF-related apoptosis-inducing ligand mediates tumoricidal activity of human monocytes stimulated by Newcastle disease virus. J Immunol. 2003;170(4):1814-1821.

84. Buckland FE, Bynoe ML, Tyrrell DA. Experiments on the spread of colds. II. Studies in volunteers with coxsackievirus A21. J Hyg (Lond). 1965;63(3):327-343

85. Couch RB, Cate TR, Gerone PJ, et al. Production of illness with a smallparticle aerosol of coxsackie A21. J Clin Invest. 1965;44:535-542.

86. Spickard A, Evans H, Knight V, Johnson K. Acute respiratory disease in normal volunteers associated with Coxsackie A-21 viral infection. III. Response to nasopharyngeal and enteric inoculation. J Clin Invest. $1963 ; 42: 840-852$.

87. Miyamoto $\mathrm{S}$, Inoue $\mathrm{H}, \mathrm{Nakamura} \mathrm{T}$, et al. Coxsackievirus B3 is an oncolytic virus with immunostimulatory properties that is active against lung adenocarcinoma. Cancer Res. 2012;72(10):2609-2621.

88. Errington F, Steele L, Prestwich R, et al. Reovirus activates human dendritic cells to promote innate antitumor immunity. J Immunol. 2008;180(9):6018-6026.

89. Benencia F, Courreges MC, Conejo-Garcia JR, et al. HSV oncolytic therapy upregulates interferon-inducible chemokines and recruits immune effector cells in ovarian cancer. Mol Ther. 2005;12(5):789-802.

90. Zhang Y, Chirmule N, Gao GP, et al. Acute cytokine response to systemic adenoviral vectors in mice is mediated by dendritic cells and macrophages. Mol Ther. 2001;3(5 Pt 1):697-707.

91. Pichlmair A, Reis e Sousa C. Innate recognition of viruses. Immunity. 2007;27(3):370-383.

92. Jablonska J, Leschner S, Westphal K, Lienenklaus S, Weiss S. Neutrophils responsive to endogenous IFN-beta regulate tumor angiogenesis and growth in a mouse tumor model. $J$ Clin Invest. 2010;120(4): 1151-1164.

93. Prestwich RJ, Errington F, Ilett EJ, et al. Tumor infection by oncolytic reovirus primes adaptive antitumor immunity. Clin Cancer Res. 2008;14(22):7358-7366.

94. Norman KL, Hirasawa K, Yang AD, Shields MA, Lee PW. Reovirus oncolysis: the Ras/RalGEF/p38 pathway dictates host cell permissiveness to reovirus infection. Proc Natl Acad Sci U S A. 2004;101(30): 11099-11104.

95. Golden JW, Linke J, Schmechel S, Thoemke K, Schiff LA. Addition of exogenous protease facilitates reovirus infection in many restrictive cells. J Virol. 2002;76(15):7430-7443.

96. Marcato P, Shmulevitz M, Pan D, Stoltz D, Lee PW. Ras transformation mediates reovirus oncolysis by enhancing virus uncoating, particle infectivity, and apoptosis-dependent release. Mol Ther. 2007;15(8): $1522-1530$

97. Alain T, Kim TS, Lun X, et al. Proteolytic disassembly is a critical determinant for reovirus oncolysis. Mol Ther. 2007;15(8): $1512-1521$.

98. Smakman N, van den Wollenberg DJ, Borel Rinkes IH, Hoeben RC, Kranenburg O. Sensitization to apoptosis underlies KrasD12-dependent oncolysis of murine $\mathrm{C} 26$ colorectal carcinoma cells by reovirus T3D. J Virol. 2005;79(23):14981-14985.

99. Adair RA, Roulstone V, Scott KJ, et al. Cell carriage, delivery, and selective replication of an oncolytic virus in tumor in patients. $S c i$ Transl Med. 2012;4(138):138ra177.

100. Norman KL, Coffey MC, Hirasawa K, et al. Reovirus oncolysis of human breast cancer. Hum Gene Ther. 2002;13(5):641-652.

101. Alain T, Hirasawa K, Pon KJ, et al. Reovirus therapy of lymphoid malignancies. Blood. 2002;100(12):4146-4153.

102. Hirasawa K, Nishikawa SG, Norman KL, Alain T, Kossakowska A, Lee PW. Oncolytic reovirus against ovarian and colon cancer. Cancer Res. 2002;62(6):1696-1701. 
103. Hingorani P, Zhang W, Lin J, Liu L, Guha C, Kolb EA. Systemic administration of reovirus (Reolysin) inhibits growth of human sarcoma xenografts. Cancer. 2011;117(8):1764-1774.

104. Wilcox ME, Yang W, Senger D, et al. Reovirus as an oncolytic agent against experimental human malignant gliomas. J Natl Cancer Inst. 2001;93(12):903-912.

105. Kilani RT, Tamimi Y, Hanel EG, et al. Selective reovirus killing of bladder cancer in a co-culture spheroid model. Virus Res. 2003;93(1): $1-12$.

106. Etoh T, Himeno Y, Matsumoto T, et al. Oncolytic viral therapy for human pancreatic cancer cells by reovirus. Clin Cancer Res. 2003;9(3): 1218-1223.

107. Loken SD, Norman K, Hirasawa K, Nodwell M, Lester WM, Demetrick DJ. Morbidity in immunosuppressed (SCID/NOD) mice treated with reovirus (dearing 3) as an anti-cancer biotherapeutic. Cancer Biol Ther. 2004;3(8):734-738.

108. Connolly JL, Rodgers SE, Clarke P, et al. Reovirus-induced apoptosis requires activation of transcription factor NF-kappaB. J Virol. 2000;74(7):2981-2989.

109. Clarke P, Meintzer SM, Spalding AC, Johnson GL, Tyler KL. Caspase 8-dependent sensitization of cancer cells to TRAIL-induced apoptosis following reovirus-infection. Oncogene. 2001;20(47):6910-6919.

110. Clarke P, Tyler KL. Down-regulation of cFLIP following reovirus infection sensitizes human ovarian cancer cells to TRAIL-induced apoptosis. Apoptosis. 2007;12(1):211-223.

111. Smakman N, van der Bilt JD, van den Wollenberg DJ, Hoeben RC, Borel Rinkes IH, Kranenburg O. Immunosuppression promotes reovirus therapy of colorectal liver metastases. Cancer Gene Ther. 2006;13(8):815-818.

112. Thirukkumaran CM, Luider JM, Stewart DA, et al. Biological purging of breast cancer cell lines using a replication-competent oncolytic virus in human stem cell autografts. Bone Marrow Transplant. 2005;35(11): 1055-1064.

113. Qiao J, Wang H, Kottke T, et al. Cyclophosphamide facilitates antitumor efficacy against subcutaneous tumors following intravenous delivery of reovirus. Clin Cancer Res. 2008;14(1):259-269.

114. Russell SJ, Peng KW, Bell JC. Oncolytic virotherapy. Nat Biotechnol. 2012;30(7):658-670

115. Cattaneo R, Miest T, Shashkova EV, Barry MA. Reprogrammed viruses as cancer therapeutics: targeted, armed and shielded. Nat Rev Microbiol. 2008;6(7):529-540.

116. Mastrangelo MJ, Maguire HC Jr, Eisenlohr LC, et al. Intratumoral recombinant GM-CSF-encoding virus as gene therapy in patients with cutaneous melanoma. Cancer Gene Ther. 1999;6(5):409-422.

117. Kim JH, Oh JY, Park BH, et al. Systemic armed oncolytic and immunologic therapy for cancer with JX-594, a targeted poxvirus expressing GM-CSF. Mol Ther. 2006;14(3):361-370.
118. Breitbach CJ, Burke J, Jonker D, et al. Intravenous delivery of a multimechanistic cancer-targeted oncolytic poxvirus in humans. Nature. 2011;477(7362):99-102.

119. Parato KA, Breitbach CJ, Le Boeuf F, et al. The oncolytic poxvirus JX-594 selectively replicates in and destroys cancer cells driven by genetic pathways commonly activated in cancers. Mol Ther. 2012;20(4):749-758.

120. Senzer NN, Kaufman HL, Amatruda T, et al. Phase II clinical trial of a granulocyte-macrophage colony-stimulating factor-encoding, second-generation oncolytic herpesvirus in patients with unresectable metastatic melanoma. J Clin Oncol. 2009;27(34):5763-5771.

121. Ockert D, Schirrmacher V, Beck N, et al. Newcastle disease virusinfected intact autologous tumor cell vaccine for adjuvant active specific immunotherapy of resected colorectal carcinoma. Clin Cancer Res. 1996;2(1):21-28.

122. Karcher J, Dyckhoff G, Beckhove P, et al. Antitumor vaccination in patients with head and neck squamous cell carcinomas with autologous virus-modified tumor cells. Cancer Res. 2004;64(21):8057-8061.

123. Steiner HH, Bonsanto MM, Beckhove $\mathrm{P}$, et al. Antitumor vaccination of patients with glioblastoma multiforme: a pilot study to assess feasibility, safety, and clinical benefit. J Clin Oncol. 2004;22(21): 4272-4281.

124. Haas C, Lulei M, Fournier P, Arnold A, Schirrmacher V. A tumor vaccine containing anti-CD3 and anti-CD28 bispecific antibodies triggers strong and durable antitumor activity in human lymphocytes. Int $J$ Cancer. 2006;118(3):658-667.

125. Au GG, Lincz LF, Enno A, Shafren DR. Oncolytic coxsackievirus A21 as a novel therapy for multiple myeloma. Br J Haematol. 2007;137(2): 133-141.

126. Berry LJ, Au GG, Barry RD, Shafren DR. Potent oncolytic activity of human enteroviruses against human prostate cancer. Prostate. 2008;68(6):577-587.

127. Shafren DR, Au GG, Nguyen T, et al. Systemic therapy of malignant human melanoma tumors by a common cold-producing enterovirus, coxsackievirus a21. Clin Cancer Res. 2004;10(1 Pt 1):53-60.

128. Skelding KA, Barry RD, Shafren DR. Systemic targeting of metastatic human breast tumor xenografts by Coxsackievirus A21. Breast Cancer Res Treat. 2009;113(1):21-30.

129. Skelding KA, Barry RD, Shafren DR. Enhanced oncolysis mediated by Coxsackievirus A21 in combination with doxorubicin hydrochloride. Invest New Drugs. Apr 2012;30(2):568-581.

130. Au GG, Beagley LG, Haley ES, Barry RD, Shafren DR. Oncolysis of malignant human melanoma tumors by Coxsackieviruses A13, A15 and A18. Virol J. 2011;8:22.
Oncolytic Virotherapy

\section{Publish your work in this journal}

Oncolytic Virotherapy is an international, peer-reviewed, open access online journal publishing original research, study protocols, reviews, editorials and commentaries on all aspects of oncolytic virology, namely the application of oncolytic viruses for the treatment of cancer. Specific topics in the journal include: Rationale and theoretical aspects of oncolytic virotherapy including in vitro, in vivo and mathematical

Submit your manuscript here: http://www.dovepress.com/oncolytic-virotherapy-journal

\section{Dovepress}

modeling; and practical application and problem solving in the clinic including identification of potential responders through biomarkers and genetic profiling. The manuscript management system is completely online and includes a very quick and fair peer-review system, which is all easy to use. Visit http://www.dovepress.com/ testimonials.php to read real quotes from published authors. 